\title{
The $\mathbf{2 3}^{\text {rd }}$ International Course on \\ the Interfaces among Mathematics, Chemistry \& Computer Sciences, Dubrovnik, Croatia, June 16-23, 2008
}

\author{
web page: http://mcc.irb.hr
}

\author{
ABSTRaCt Submission deAdline: May 1, 2008 \\ Inter-University Center, Dubrovnik, Croatia, "Ruđer Bošković" Institute, Zagreb, Croatia \\ Universities of Zagreb \& Split \\ International Society for Mathematical Chemistry, International Society for Theoretical Chemical Physics
}

\section{Scientific Committee}
D. Butina (Cambridge)
D. J. Klein (Galveston)
R. Ponec (Prague)
P. F. Stadler (Leipzig)
J. Cioslowski (Tallahassee)
M. Randić (Des Moines)
D. Svrtan (Zagreb)
H. Hosoya (Tokyo)
H. Sachs (Ilmenau)
N. Trinajstić (Zagreb)
P. Fowler (Exeter)
I. Simon (Budapest)
H. Vančik (Zagreb)

\section{Organizing Committee}

A. Graovac (Zagreb) \& R. Todeschini (Milano), directors
M. V. Diudea (Cluj)
I. Laszlo (Budapest)
T. Pisanski (Ljubljana), co-dir.
N. Štambuk (Zagreb)
D. Janežič (Ljubljana)
D. Plavšić (Zagreb), co-dir.
D. Vikić-Topić (Zagreb), co-dir.
E. C. Kirby (Pitlochry), co-dir.
B. Pokrić (Zagreb)
J. Žerovnik (Maribor)
P. Konjevoda (Zagreb)

\section{Venue}

The MATH/CHEM/COMP 2008 COURSE (MCC 2008 COURSE) will be held in Dubrovnik from June 16-23, 2008. The courses will be held at the Inter-University Centre (IUC), don Frana Bulića 4. Dubrovnik is situated on Adriatic Coast at the far south of the Republic of Croatia, and due to its beauty and harmony it is designated by UNESCO as a world heritage.

\section{Conference Scope}

The MCC 2008 COURSE is the $23^{\text {rd }}$ in the series of MCC meetings which started in 1986 . This year only selected courses and posters will be presented. Any subject pertinent in an interdisciplinary way to mathematics and/or computer sciences and chemistry and related sciences is a legitimate topic for poster presentations at the MCC 2008 COURSE. The meeting is open to all aspects of current research in the applications of computer modeling, combinatorics, graph theory and topology to any area of chemistry, physics, materials and life sciences.

\section{Organizer}

All correspondence concerning the meeting should be addressed to: Prof. Ante Graovac, The R. Bošković Institute, HR-10002 Zagreb, POB 180, Croatia; phone: (385)-(1)-46-64-565; fax: (385)-(1)-46-80-245; e-mail: graovac@ irb.hr 
Workshop of the European Network of Excellence

Complex Metallic Alloys

\section{Frontiers in Complex Metallic Alloys}

\section{Institute of Physics \\ October 1 - 4, 2008}

\section{Zagreb, Croatia}
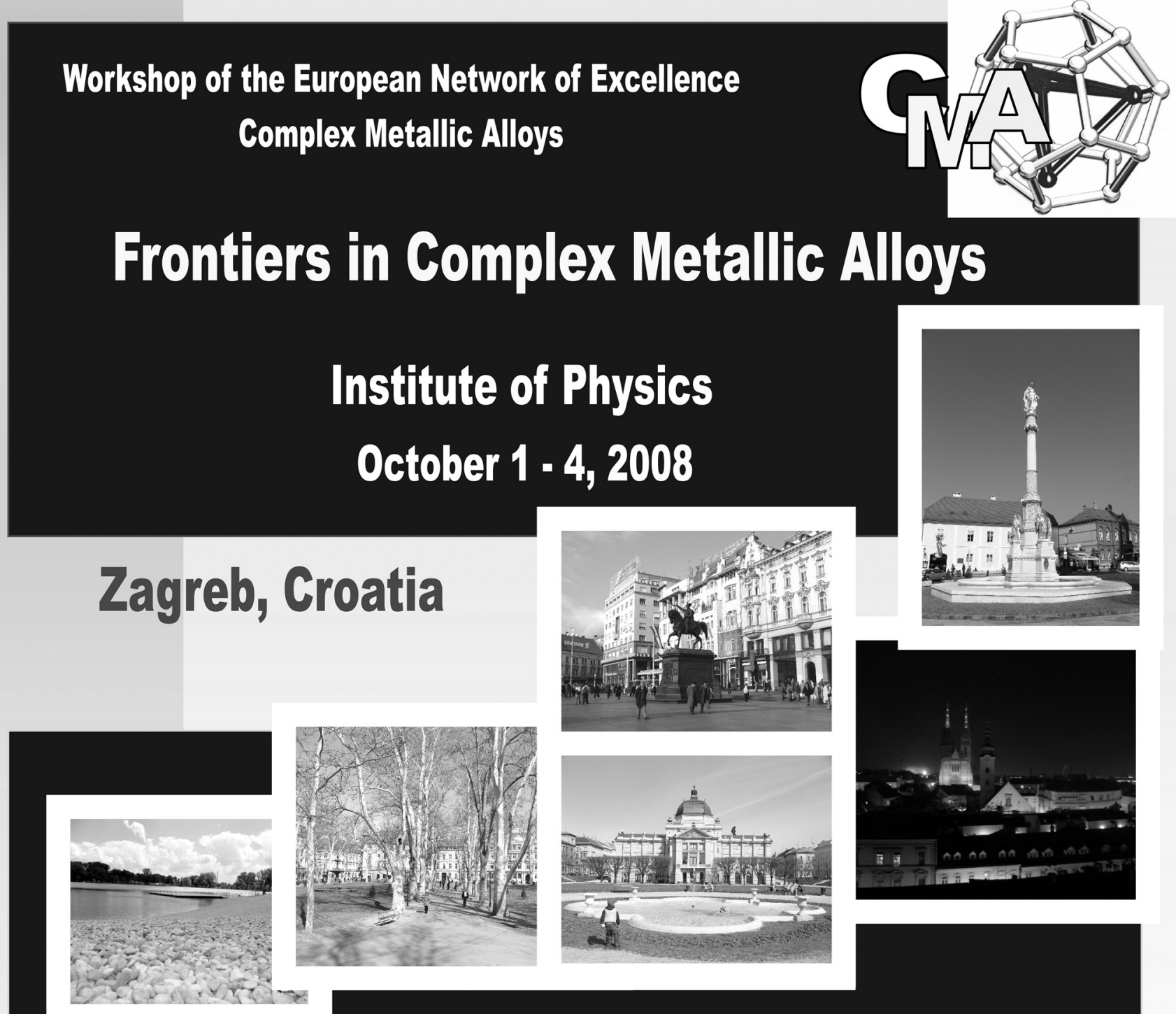

\section{Advisory Board}

E. Babić (Zagreb, Croatia)

S. Barišić (Zagreb, Croatia)

E. Belin-Ferré (Paris, France)

Y. Grin (Dresden, Germany)

W. Gulbinski (Koszalin, Poland)

B. Leontić (Zagreb, Croatia)

R. McGrath (Liverpool, UK))

S. Musić (Zagreb, Croatia)

B. Pivac (Zagreb, Croatia)

S. Popović (Zagreb, Croatia)

W. Steiner (Wien, Austria)

H. R. Trebin (Stuttgart, Germany)

C. Vahlas (Toulouse, France)

\section{Chair Persons}

A. Smontara (Zagreb, Croatia)

J.-M. Dubois (Nancy, France)

J. Dolinšek (Ljubljana, Slovenia)

\section{Program Committee}

I. Batistić (Zagreb, Croatia)

A. Bilušić (Split, Croatia)

M. de Boissieu (Grenoble, France)

S. Bühler-Pashen (Wien, Austria)

M. Feuerbacher (Jülich, Germany)

N. Radić (Zagreb, Croatia)

W. Steurer (Zürich, Switzerland)

E. Tutiš (Zagreb, Croatia)
Local Organizing Committee

N. Barišić (Zagreb, Croatia) I. Batistić (Zagreb, Croatia)

J. Ivkov (Zagreb, Croatia)

J. Lukatela (Zagreb, Croatia)

P. Popčević (Zagreb, Croatia)

D. Stanić (Osijek, Croatia)

\section{Coorganizers}

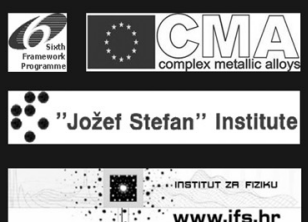


Editorial work concluded on January 14, 2008.

Annual subscription rates: Croatian Chemical Society members $15.00 €$, institutions and companies $80.00 €$.

For the publisher: Nikola Kallay, Editor-in-Chief, Horvatovac 102 a, HR-10001 Zagreb. Editorial office: Horvatovac 102 a, HR-10000 Zagreb. Bank account for Croatia is 2360000-1101387722 Zagrebačka banka (att. to Hrvatsko kemijsko društvo, Zagreb) payable in kuna, equivalent to the mentioned subscription rate. Bank account for foreigners is 2500-840-2400027680-070 Zagrebačka banka (att. to Hrvatsko kemijsko društvo, Zagreb).

Printed by: LASER plus, Brijunska 1a, Zagreb

The Home Page of Croat. Chem. Acta including all the Tables of Contents since 1996 and articles in the pdf since 1998 may be found on the www under http://public.carnet.hr/ccacaa/

Parts of the contents of Croatica Chemica Acta (e.g. figures or tables) may be reproduced without prior permission, provided reference is made to their source.

Photocopies of the articles are available through The Genuine Article ${ }^{(\mathrm{R})}$ delivery program from:

Institute for Scientific Information

3501 Market Street

Philadelphia, PA 19104 USA 

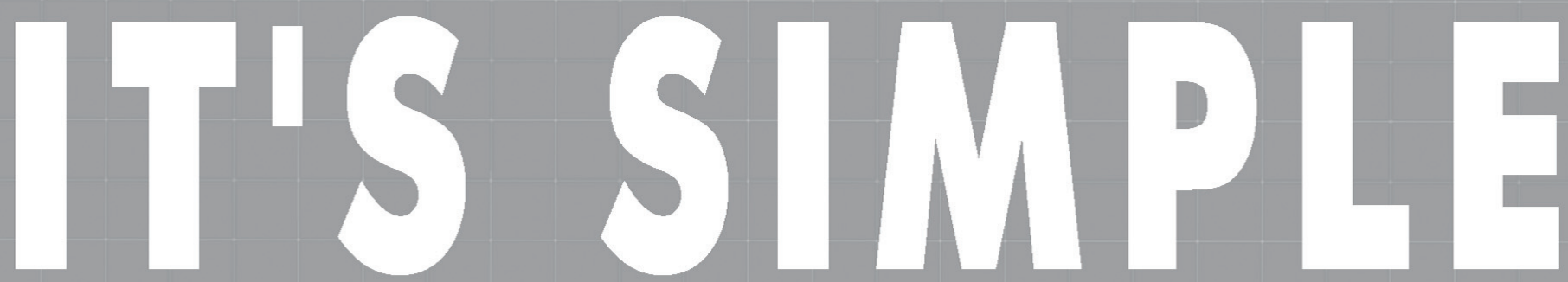

...beccuse we know how to create...
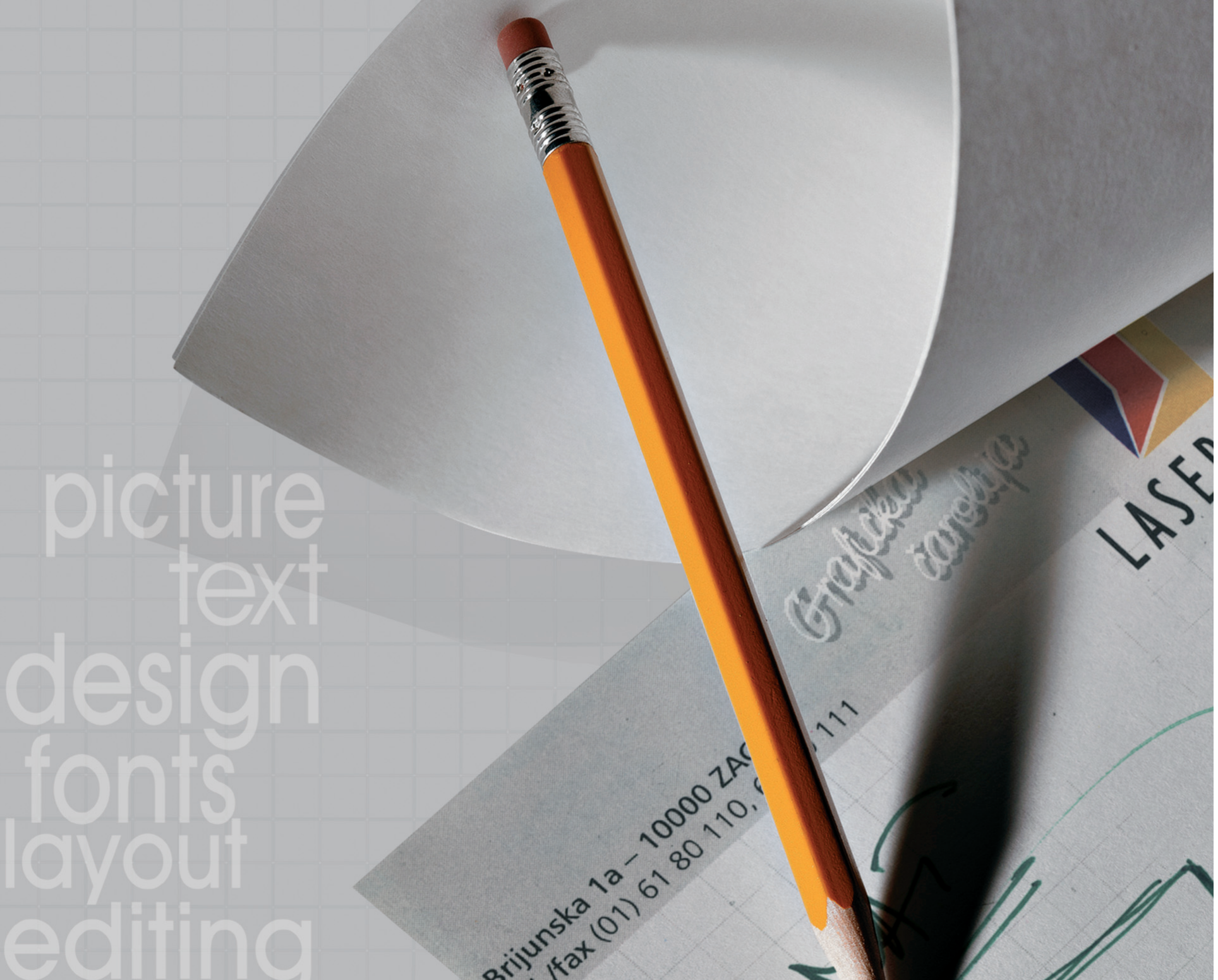

match pintin

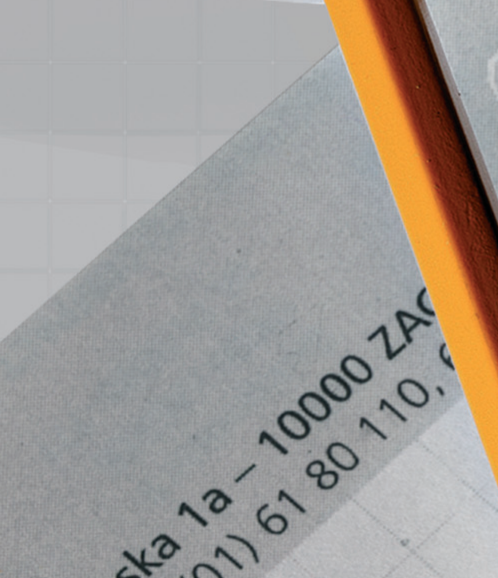

(6)
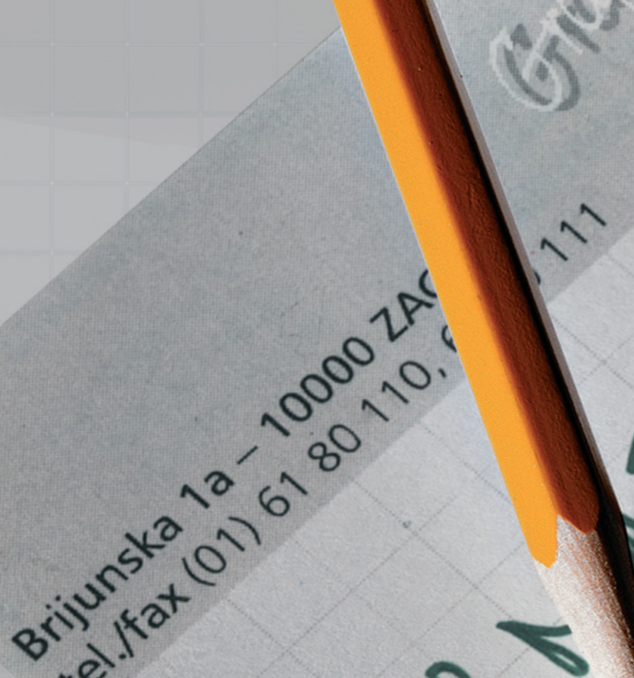

(0)

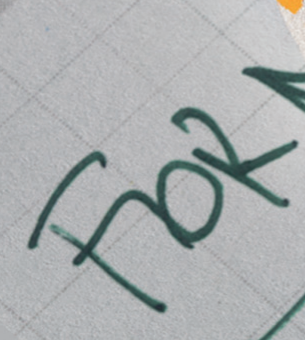

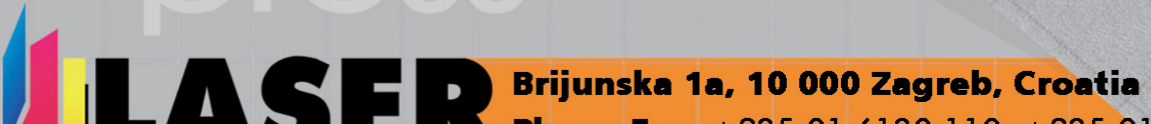

Phone.Fax: +385.01.6180110, +385.01.6180111, E-malil: laser-plus@zg.hinet.hr_. plus

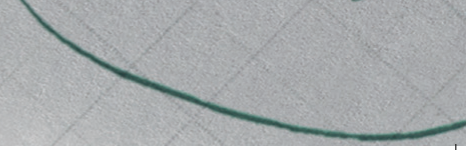

$\theta$ 